\title{
The epidemiology of obstructive sleep apnoea and cardiovascular disease
}

\author{
Paroma Sarkar $^{1}$, Sutapa Mukherjee ${ }^{1,2}$, Ching Li Chai-Coetzer ${ }^{1,2}$, R. Doug McEvoy ${ }^{2}$ \\ ${ }^{1}$ Sleep Health Service, Respiratory and Sleep Services, Southern Adelaide Local Health Network, Adelaide, South Australia, Australia; ${ }^{2}$ Adelaide \\ Institute for Sleep Health, Flinders University, Bedford Park, South Australia, Australia \\ Contributions: (I) Conception and design: All authors; (II) Administrative support: None; (III) Provision of study materials or patients: None; (IV) \\ Collection and assembly of data: All authors; (V) Data analysis and interpretation: All authors; (VI) Manuscript writing: All authors; (VII) Final \\ approval of manuscript: All authors. \\ Correspondence to: Dr. Paroma Sarkar. Sleep Fellow, Department of Respiratory and Sleep Services, Flinders Medical Centre, Flinders Drive, Bedford \\ Park, SA 5042, Australia. Email: paroma.sarkar@gmail.com
}

\begin{abstract}
Obstructive sleep apnoea, the most common form of sleep-disordered breathing, is highly prevalent in patients with cardiovascular disease. The last 30 years has seen a plethora of large scale epidemiological studies investigating the relationship between sleep apnoea and cardiovascular outcomes. This review highlights the key epidemiological studies addressing the links between sleep apnoea and hypertension, cardiac arrhythmias, cerebrovascular disease, coronary artery disease, heart failure and pulmonary hypertension, with a particular focus on some of the most recent reports.
\end{abstract}

Keywords: Epidemiology; obstructive sleep apnoea (OSA); cardiovascular

Submitted Jun 24, 2018. Accepted for publication Dec 01, 2018.

doi: $10.21037 /$ jtd.2018.12.56

View this article at: http://dx.doi.org/10.21037/jtd.2018.12.56

\section{Introduction}

Obstructive sleep apnoea (OSA) is the most common type of sleep disordered breathing. It is characterised by repetitive partial or complete closure of the upper airways in sleep, which leads to a reduction or absence of airflow and arousal (1). A diagnosis of OSA is ideally made using overnight polysomnography (PSG) with up to 12 recording channels including nasal and oral airflow, respiratory effort transducers, EEG and EMG and oximetry. Simplified, lower cost devices with fewer channels have also been validated. The number of apnoeas and hypopnoeas per hour of sleep, the apnoea hypopnea index (AHI), is used to determine the presence and severity of OSA. An AHI of more than $5-10$ events/hr is considered diagnostic of OSA. The most common reported symptoms of OSA are related to the upper airway obstruction itself (e.g., snoring, witnessed apnoeas) and the effects of the obstructions on sleep (e.g., occasional gasping arousals, excessive daytime somnolence, general fatigue and depressed mood). However, recent evidence suggests that in up to $40 \%$ of OSA patients the predominant symptoms are more akin to those of insomnia (i.e., difficulty initiating or maintaining sleep), while in others there may be very few if any reported symptoms $(2,3)$. These latter two previously unappreciated symptom profiles (or OSA "phenotypes") may have led to significant under recognition of the disease in the past.

Although several large-scale epidemiological studies have estimated the prevalence of OSA, differences in recording or scoring methods and in the threshold AHI score used to diagnose sleep apnea as well as varied population sampling schemes, have led to variable results. The first and most widely quoted study, the Wisconsin Sleep Cohort study, recently reported the prevalence of moderate to severe OSA (i.e., AHI $\geq 15$ events per hour) among $30-70$ years old participants to be $10 \%$ (95\% CI, $8-11 \%$ ) (4). The authors concluded that, depending on the age and gender subgroup, this represented a $14 \%$ to $55 \%$ increase in OSA prevalence over that measured in the same cohort 20 years before $(5,6)$. A much higher prevalence of moderate to severe OSA (50\% 
in men, $23 \%$ in women) has subsequently been reported in a Swiss community study (7) and in a study of Australian men $(26 \%)$ (8), although it seems this increase might be explained, in part, by the greater sensitivity of recent sleep study recording and scoring methods $(7,9)$.

Some of the earliest observational studies reported an association between snoring, used as a surrogate of sleep apnoea, and cardiovascular (CV) disease (10). Since then, large scale epidemiological studies have confirmed the association between OSA (measured by sleep study) and $\mathrm{CV}$ disease (11-13) with the increased risk remaining after correction for common CV risk factors (14). It is well known that the metabolic syndrome, which is defined by the presence of obesity, hypertension, insulin resistance and hyperlipidemia, increases the risk of cardiovascular disease. A systematic review examining the relationship between OSA and the metabolic syndrome reported an odds ratio (OR) for metabolic syndrome in individuals with OSA of 2.87 (95\% CI, 2.41-3.42) in cross-sectional studies and 2.56 (95\% CI, 1.98-3.31) in case control studies (15). However, whether OSA is simply a "bystander" in the metabolic syndrome or is driving an increase in metabolic burden is yet to be properly elucidated. Emerging research suggests that the hypoxic burden caused by OSA has a significant role to play in the development of cardiovascular disease. In a cohort study of 2,872 older male patients, patients with severe nocturnal hypoxaemia, defined as more than $10 \%$ of the night spent with oxygen saturations $<90 \%$, had a 1.8 fold increased risk of stroke compared to those without nocturnal hypoxia (95\% CI, 1.12-2.98) (16). Another prospective study, in which PSGs were performed on 112 patients who suffered a myocardial infarct, found that nocturnal hypoxaemia, defined as desaturations to a nadir of $<85 \%$, was an independent risk factor for major adverse cardiac events (HR 6.05, $\mathrm{P}=0.004)$ (17).

The hypoxic burden in OSA is strongly weighted by REM related sleep disordered breathing. REM sleep accounts for about $15-25 \%$ of total sleep time in healthy subjects and occurs predominantly in the second part of the night. This important stage of sleep is characterised by decreased muscle tone, rapid eye movements, a change in respiratory pattern and dreaming. Due to the increased collapsibility of the upper airways from hypotonia, obstructive events in REM sleep are usually longer and associated with greater oxygen desaturation than those seen in non-REM sleep. Isolated REM OSA is seen in 10-37\% of patients referred for investigation of OSA (18).

In this chapter, we will review the epidemiology linking OSA with hypertension, cardiac arrhythmias, cerebrovascular disease, coronary artery disease, heart failure and pulmonary hypertension and focus on some recent studies that provide new insights into how phenotypic variants, such as REM predominant OSA, might impact on CV risk.

\section{Pathophysiology of the cardiovascular consequences of OSA}

A detailed description of the diverse and complex pathways involved in the association of OSA and cardiovascular disease has been discussed in the previous chapter.

In brief, the intermittent hypoxia observed in OSA leads to oxidative stress, increased sympathetic activation, endothelial dysfunction, blood pressure surges, an increase in the levels of circulating inflammatory markers and hypercoagulability. Large negative intrathoracic swings generated by obstructed breathing efforts also place considerable mechanical stress on the heart and great vessels. Together these changes create an environment that has the potential to promote atherosclerosis $(19,20)$ and increase the risk of coronary artery disease $(\mathrm{CAD})$ and stroke (19).

\section{Hypertension}

Hypertension is arguably the single most important risk factor for cardiovascular disease. OSA and hypertension commonly co-occur: the reported prevalence of OSA amongst patients with hypertension varies between $20-40 \%$, increasing to $70 \%$ in those with drug resistant hypertension (21). The association between OSA and hypertension has been the subject of intense investigation in both community and clinic populations, in an attempt see if the two conditions might be causally linked.

\section{OSA and prevalent hypertension}

The majority of the cross-sectional studies have shown that the risk of hypertension increases with increasing severity of OSA. Two of the earliest community-based cohort studies to examine the cross sectional relationship between hypertension and OSA were the Wisconsin Sleep Cohort (WSC) (22) and the Sleep Heart Health Study (SHHS) (23). The WSC study showed a linear relationship between hypertension and severity of OSA in a sample of 1,060 men and women aged between 30-60 years after correcting for age, gender and body mass index (BMI). 
Table 1 Prevalence of hypertension in obstructive sleep apnoea

\begin{tabular}{|c|c|c|c|c|}
\hline Study & Sample size and gender & Methodology & Definition of hypopnoea & $\begin{array}{l}\text { OR for hypertension when } \\
\mathrm{AHI}>10-15 \text { events/hr }\end{array}$ \\
\hline Young et al. [1997] (22) & $\begin{array}{l}\text { 1,069 adults ( } 30-60 \text { years); } \\
\text { M: } 617 ; \mathrm{F}: 452\end{array}$ & Attended PSG & $\begin{array}{l}50 \% \text { reduction in airflow for a } \\
\text { minimum of } 10 \mathrm{~s} \text { with oxygen } \\
\text { desaturation of } \geq 4 \%\end{array}$ & 1.8 (95\% Cl, 1.3-2.4) \\
\hline Lavie et al. [2000] (27) & $\begin{array}{l}\text { 2,677 adults (20-85 years); } \\
\text { M: 1,949; F: } 728\end{array}$ & Attended PSG & $\begin{array}{l}50 \% \text { reduction in airflow for a } \\
\text { minimum of } 10 \mathrm{~s} \text { with oxygen } \\
\text { desaturation of } \geq 4 \% \text { or an arousal }\end{array}$ & 1.12 (95\% Cl, 0.75-1.56) \\
\hline Bixler et al. [2000] (25) & $\begin{array}{l}1,741 \text { adults }(20-100 \text { years); } \\
\text { M: } 741 ; \mathrm{F}: 1,000\end{array}$ & Attended PSG & $\begin{array}{l}50 \% \text { reduction in airflow for a } \\
\text { minimum of } 10 \text { s with oxygen } \\
\text { desaturation of } \geq 4 \%\end{array}$ & 6.8 (95\% Cl, 2.02-26.36) \\
\hline Nieto et al. [2000] (23) & $\begin{array}{l}6,132 \text { adults ( } \geq 40 \text { years); } \\
\text { F: } 3,238 ; M: 2,894\end{array}$ & $\begin{array}{l}\text { Home unattended } \\
\text { PSG }\end{array}$ & $\begin{array}{l}30 \% \text { reduction in airflow for a } \\
\text { minimum of } 10 \mathrm{~s} \text { with oxygen } \\
\text { desaturation of } \geq 4 \%\end{array}$ & 1.37 (95\% Cl, 1.03-1.83) \\
\hline
\end{tabular}

PSG, polysomnography.

The risk of hypertension increased by $4 \%$ for every 1 event/hr increase in the AHI (22). The association appeared to be strongest when BMI was lowest. The SHHS studied an older cohort of subjects: above 40 years of age. Cross sectional analysis of the 6,132 subjects who underwent home based unattended PSG showed an increased risk of having hypertension when the AHI was $\geq 30$ events/hr versus when the AHI was $\leq 1.5$ events/hr (OR 1.37; 95\% CI, 1.03-1.83) after adjustment for BMI and demographics (23). It is important to note however, that above the age of 60 years, there was no significant association between hypertension at any severity of OSA (24). This is similar to the findings subsequently described in a separate study by Bixler and colleagues (25). In this population cohort of 1,741 adults, the odds ratio for hypertension increased with severity of the OSA, however, as in the SHHS the strength of this association reduced with older age. Several hypotheses have been suggested to explain this lack of association between hypertension and OSA in elderly subjects. It could be attributed to selection bias given the cross sectional nature of the studies, but it is conceivable also that in older patients there is a different phenotypic expression of sleep apnea (e.g., higher proportion of mixed and central apneas) (26) or co-existing medical illnesses that affect the relationship (24). A Canadian population-based crosssectional study of 2,677 adults aged 20-85 years also demonstrated a linear relationship between hypertension and severity of sleep apnoea after adjustment for age, BMI and sex. Logistic regression models showed that an increase in 10 apneic events per hour of sleep increased the risk of hypertension by $11 \%$ ( $\beta$ coefficient 0.01 ) (27) This group also looked at the relationship between oxygen desaturation and hypertension and reported that for each $10 \%$ decrease in the saturation nadir, the risk of prevalent hypertension increased by $13 \%$ ( $\beta$ coefficient 0.013 ) (27). The ESADA study, a multi-centre cross sectional study of 8,533 patients, compared the predictive value of the AHI versus the oxygen desaturation index (ODI) for prevalent hypertension. After adjustment, the logistic regression models showed that the ODI was a significant predictor of prevalent hypertension whereas the AHI was not: OR 2.01 (95\% CI, 1.61-2.51) for $4^{\text {th }} v s .1^{\text {st }}$ quartiles of the $4 \%$ ODI; OR 0.92 (95\% CI, 0.74-1.15) for 4th vs. 1st quartiles of AHI (28). Although collectively these cross-sectional studies show an association between hypertension and OSA, the reported odds ratios for hypertension vary considerably (Table 1). Age, baseline anthropometrics and ethnic differences may contribute to this variance.

\section{OSA and incident hypertension}

In a follow up study of the WSC, 709 participants were followed for 4 years after enrolment. After correcting for confounding factors such as baseline hypertension status, age, gender, smoking and alcohol intake, the risk of developing hypertension increased with increasing severity of OSA: OR of 1.42 (95\% CI, 1.13-1.78) with an AHI 0.1-4.9 events/hr, 2.03 (95\% CI, 1.29-3.17) for an AHI 
of 5-14.9 events/hr and 2.89 (95\% CI, 1.46-5.64) for an AHI $>15$ events/hr relative to the reference category of an AHI of 0 events/hr at baseline (11). In a sleep centre in Spain, a cohort of 1,180 patients who were normotensive at baseline was followed for 7 years. Patients with OSA were subdivided into 4 groups based on their CPAP treatment status: (I) Ineligible for CPAP treatment according to the national guidelines (II) eligible for CPAP treatment but declined by patient (III) non-compliant with CPAP treatment post initiation (IV) compliant and on treatment with CPAP. After adjusting for baseline AHI, age, sex, systolic and diastolic blood pressure and BMI, patients with untreated OSA had a higher HR of incident hypertension compared to the control group with no OSA, and the OSA group who were compliant with CPAP treatment had a significantly lower hazard ratio compared to those with untreated OSA (29). Contradicting the above two studies, a 5-year follow up of 2,470 patients from the SHHS who were normotensive at baseline did not show an increased risk of incident hypertension after adjustment for BMI (30). Similarly, the Spanish Vitoria Sleep cohort study of 1,180 people between the ages of 30-70 years who had baseline home based PSG and anthropometric measures and were followed up for 7.5 years found no statistically significant association between OSA and incident hypertension after adjusting for age, BMI, neck circumference, fitness level and social habits such as smoking and alcohol intake (31). More recently REM OSA has been shown to be associated with the development of incident hypertension in patients from the WSC (32). Non-dipping of nocturnal blood pressure, defined as less than $10 \%$ decrease in nocturnal blood pressure, has been associated with incident hypertension and adverse cardiovascular outcomes $(33,34)$. A subsequent study from the WSC looked specifically at the relationship between REM OSA and incident non-dipping of nocturnal blood pressure. In this group of 414 patients, those with REM AHI $>15$ events/hr had a higher relative risk (RR) of incident systolic (2.84, 95\% CI, 1.1.0-7.29) and diastolic (4.27, 95\% CI, 1.20-15.13) non-dipping of blood pressure. Further supporting this, it was found in a community cohort of men that REM only OSA (defined as REM AHI $\geq 20$ events/hr, overall AHI $<10$ events per hour) was independently associated with prevalent hypertension (35).

Overall, the available data supports an association between hypertension and OSA but the demonstration of causality is lacking. The results of longitudinal studies exploring the link between OSA and incident hypertension are equivocal and there are no randomized controlled trial data, to date, showing that CPAP treatment reduces the risk of developing hypertension, or the reliance on anti-hypertensive medications in OSA patients who are hypertensive (36). There is a need for further longitudinal studies, preferably including participants who are free of both hypertension and OSA at baseline, to study the order of cause and effect as both diseases evolve. Treatment with CPAP leads to modest improvements in blood pressure and the effects are best seen in compliant patients with resistant hypertension (37). Drug treatment and lifestyle modification remain the cornerstones of treatment for hypertension (38).

\section{Cardiac arrhythmias}

Cardiac arrhythmias are relatively common in patients with OSA with up to $50 \%$ of patients having at least one nocturnal arrhythmia (39). OSA has been predominantly associated with paroxysmal atrial fibrillation (AF), bradyarrhythmias and premature ventricular complexes (PVCs) (40).

\section{$\mathrm{AF}$}

It is postulated that OSA provides both chronic and acute "substrates" for the development of AF (41). Obstructive events in sleep lead to large swings in intrathoracic pressure which results in stretching of the thin walled atria, and this acute stretch impairs normal conduction pathways. Chronicity of the atrial stretch and progressive mechanical atrial distension leads to remodeling of the atria. Sympathetic activation and vagal bradycardia at the end of an apnoea causes electrophysiological changes and the combination of the above provide an environment that is primed for arrhythmogenesis (41).

\section{Prevalence}

In the SHHS, the prevalence of nocturnal atrial AF in participants with OSA was $5 \%$, which compared to $1 \%$ in age, sex, race/ethnicity and BMI-matched participants without OSA (40). In cohorts of patients with concurrent heart failure and CAD, those who had co-existent OSA had an even higher prevalence of $\mathrm{AF}(42,43)$. The converse may also be true: the prevalence of OSA estimated from the Berlin questionnaire (44) and by sleep study (45) was significantly higher amongst patients with AF than in control patients without AF with the study using the Berlin questionnaire showing an adjusted $\mathrm{OR}$ for the association of AF and OSA of 2.19 (95\% CI, 1.4-3.42, P=0.0006) 
and the study using portable PSG showing an OR for the association between $\mathrm{AF}$ and sleep disordered breathing of 3.04 (95\% CI, 1.24-7.46, $\mathrm{P}=0.02$ ).

\section{Incident AF}

A recent meta-analysis of 8 cohort studies showed that the presence of OSA increases the risk of developing AF with a RR of 1.70 (95\% CI, 1.53-1.89) (46). This appeared to occur in a dose dependent fashion: RR 1.52 (95\% CI, $1.28-1.79), 1.88(1.55-2.27)$ and $2.16(1.78-2.62)$ for mild, moderate and severe OSA respectively (46). In a retrospective cohort study of 3,452 adults who had sleep studies, independent predictors of incident $\mathrm{AF}$ in subjects $<65$ years were known risk factors such as age, male gender, $\mathrm{CAD}$ and $\mathrm{BMI}$ but also the presence of nocturnal hypoxia, the latter increasing the risk of incident $\mathrm{AF}$ threefold after correcting for obesity (47). Other features of sleep apnoea such as AHI and arousal index were not independently associated with AF, suggesting a dominant role for apnearelated de-oxygenation/re-oxygenation. A recent metaanalysis (48) also showed that the risk of recurrence of AF was increased by $25 \%$ following catheter ablation in patients if they had concurrent OSA. Data from uncontrolled interventional studies tends to support the theory that CPAP treatment reduces paroxysmal AF (49) however the lack of randomised controlled trials (RCT) focused on OSA therapy and recurrence of AF makes it difficult to draw firm conclusions at this time.

\section{Bradyarrhythmias}

Bradyarrhythmias are observed in up to $18 \%$ of patients with severe OSA in the absence of any co-existing cardiac disorders (50). This is a six-fold increase compared to the prevalence of bradyarrhythmias in a healthy population of adults between the ages of 60-85 years (51). Conduction delay arrhythmias such as sinus pauses and atrioventricular (AV) nodal blocks have been anecdotally seen in patients with OSA however epidemiologic studies have shown the association to be limited to those with severe sleep apnoea (AHI $\geq 30$ events/hr) and those who have the most significant nocturnal hypoxia (50). Atrioventricular nodal blocks in particular have been seen predominantly in REM sleep when along with increased sympathetic activity, parasympathetic tone is also enhanced and apnoeas are more prolonged with subsequently greater oxygen desaturation (52).

\section{PVCs}

Ventricular arrhythmias are classified as ventricular tachycardias, fibrillation and premature contractions. PVCs are the most common type of ventricular arrhythmia encountered in patients with OSA and are predominantly seen at the end of apnoeic episodes around the time of the oxygen desaturation nadir (53). The prevalence of PVCs has been reported to range between $14 \%$ and $74 \%$ in patients with OSA compared with only $5 \%$ in the general population (50). The wide range in prevalence is thought to be due to differences in OSA severity in the cohort studies and also the variable presence of concurrent cardiovascular disease (53). It should also be noted, however, that not all studies report a positive association between OSA and increased PVCs. Olmetti et al. reviewed the ECG tracings from the PSGs of 247 patients with OSA and observed the prevalence of PVCs to be similar to the estimated rate in the general population (9\%) and the prevalence did not increase with worsening severity of OSA (54).

The interventional studies in the different arrhythmia groups will be discussed in later chapters but in general have yielded mixed results (50). The clinical implications of nocturnal arrhythmias vary according to the type of the arrhythmia (e.g., occasional PVCs vs. rapid symptomatic $\mathrm{AF}$ ) and thus far it is unknown whether or not suppressing certain arrhythmias which are thought to be more "benign" like PVCs improves clinical outcomes.

\section{Cerebrovascular disease}

Large well-designed prospective studies have shown that the presence of OSA increases the risk of incident stroke by up to 2-3 times (55). Potential mechanisms linking OSA with stroke include an alteration in cerebral perfusion during apneic episodes, OSA-induced hypertension, mechanical disruption of carotid artery plaques due to snoring and thromboembolic stroke caused by OSA-induced AF (56).

\section{Prevalence of OSA in stroke}

A recent meta-analysis reported the prevalence of OSA to be $61.4 \%$ in patients with cerebrovascular disease (57). The prevalence was particularly high in males and those with stroke of unknown aetiology.

\section{Incident stroke}

$\mathrm{AF}$ is a well-known risk factor for the development of ischaemic stroke and given the strong association between $\mathrm{AF}$ and OSA described above, it would seem likely that $\mathrm{AF}$ plays a significant role. However, a meta-analysis of 5 studies that reported on the impact of $\mathrm{AF}$ in patients with stroke 
and OSA found that its presence did not affect this risk (58). Interestingly, a retrospective cohort study at the Western Connecticut Health Network, assessed the relationship between OSA, AF and stroke from a different angle. This study, investigated the impact of OSA in patients who had $\mathrm{AF}$ and stroke. Patients with AF and no previous history of stroke who had undergone sleep studies for any reason were identified. Prevalence of first time ischaemic stroke was assessed by review of medical records by a blinded physician investigator. After controlling for age, gender and concurrent $\mathrm{CAD}$, the adjusted OR between OSA and stroke remained significant at 3.65 (95\% CI, 1.252 to 10.623$)$ and also extended to the subgroup with low $\mathrm{CHADS}_{2}$ score, suggesting OSA in patients with $\mathrm{AF}$ is an independent predictor of stroke. Furthermore, increased severity of OSA as determined by the AHI correlated with the increased rate of stroke $(\mathrm{P}=0.0045)$ (59). Sleep disordered breathing has also been associated with an increased risk of recurrent stroke (60). In a 10-year prospective follow up of a cohort of 132 patients who underwent diagnostic PSG following a stroke, the presence of OSA (defined by AHI of $\geq 15$ events/hr) was associated with an increased risk of death with a $\mathrm{HR}$ of 1.76 (95\% CI, 1.05-2.95) (61). Furthermore, the previously mentioned meta-analysis by Loke et al. found a dose dependent relationship between the severity of OSA and risk of incident stroke. An increase in AHI by 10 events/hr increased the risk of incident stroke by $36 \%$ (58).

\section{$C A D$}

\section{Prevalence of OSA in CAD}

The prevalence of OSA in patients with CAD is reported as being between $38 \%$ and $65 \%$, which is higher than that seen in the general population (62).

\section{Incident CAD}

Although many observational studies have shown an association between CAD and OSA (58), the studies looking at incident $\mathrm{CAD}$ in sleep-disordered breathing have shown variable results. In a 24 year follow up of 1,131 adults from the WSC who were free of CAD at baseline, the estimated HR of incident CAD was 2.6 (95\% CI, 1.1-6.1) in severe untreated sleep apnoea (AHI $\geq 30$ events/hr) after adjusting for gender, age, BMI and smoking habits. However, after further adjustment for hypertension and diabetes, the hazard ratios did not achieve statistical significance, although the trends remained (63). In a 9 year follow up of 4,422 patients from the SHHS who were free of CAD at baseline, severe OSA ( $\mathrm{AHI} \geq 30$ events/hr) in male patients younger than 70 years was seen to be a predictor of incident CAD with an adjusted HR of 1.13 (95\% CI, 1.02-1.26) but this association did not extend to women and older men (13).

\section{Effects of treatment of OSA on CAD}

Observational data from prospective cohort studies have shown that treating patients with OSA lowered cardiovascular morbidity and mortality within the patient cohorts $(64,65)$. One of the major criticisms of these nonrandomised studies is that patients who do not adhere to CPAP therapy may also be non-compliant with other aspects of chronic disease management and have generally less favorable lifestyle behaviors. The effects of treatment of OSA on CAD will be discussed in more detail in later chapters.

In summary, cross sectional data suggest a significant independent association between OSA and CAD. However, results from longitudinal studies are less convincing, with the association between sleep apnoea and incident CAD being weak after correction for other known risk factors, with the relationship being present in only some groups but not others (13). In patients who have established CAD, untreated sleep apnoea is associated with increased $\mathrm{CV}$ mortality (64) however the data from RCTs $(66,67)$ thus far do not support a clear reduction in risk of acute coronary events and death with OSA treatment.

\section{Heart failure}

\section{Prevalence of sleep disordered breathing in heart failure}

The prevalence of sleep-disordered breathing in patients with heart failure is of the order of $50-75 \%$ (68). The prevalence is similar in stable heart failure with preserved (HF-pEF) and reduced (HF-rEF) ejection fraction but is considerably higher in patients who present with acute decompensated heart failure $(69,70)$. Both OSA and central sleep apnoea (CSA) are observed in heart failure patients although OSA is the predominant type of sleep disordered breathing in HF-pEF (69-81\%) with CSA and CheyneStokes respiration being more common in those with HFrEF $(25-40 \%)(71,72)$.

\section{Incident heart failure in OSA}

The longitudinal SHHS study (13) found that, in men under the age of 70 years, incident heart failure was $58 \%$ more likely in those with severe sleep apnoea (AHI $\geq 30$ 
events/hr) than without sleep apnoea (AHI $<5$ events/hr). A 24 year follow up of 1,131 adults from the WSC without heart failure or $\mathrm{CAD}$ at baseline showed that those who had untreated severe sleep apnoea (AHI $>30$ events/hr) were 2.6 times more likely (95\% CI, 1.1-6.1) to develop coronary heart disease or heart failure compared to those without sleep apnea (63). Gender specific associations between incident heart failure and OSA have also been demonstrated. In a study of 1645 patients from two epidemiologic cohorts, the SHHS and the atherosclerosis risk in communities (ARIC) study, OSA severity was associated with incident heart failure as well as CAD, death and left ventricular hypertrophy in women but not men $(\mathrm{P}<0.0001$ in women and $\mathrm{P}=0.08$ in men) (73). The symptomatology of OSA in patients with heart failure is unique in that there are few symptoms, particularly daytime somnolence, which in turn can lead to an under recognition of the condition clinically (74).

\section{Pulmonary hypertension}

\section{Prevalence of OSA in patients with pulmonary hypertension}

Although OSA is considered one of the "Group 3" aetiologies in the clinical classification of pulmonary hypertension (75), its true prevalence in pulmonary hypertension is unclear. This is because most of the studies have not clearly defined OSA as an entity and have included a broad range of diagnoses such as CSA and periodic breathing during sleep. Dumitrascu et al. prospectively studied 169 patients who were diagnosed with severe pre-capillary pulmonary hypertension i.e., pulmonary hypertension that is not secondary to left heart disease, and found $27 \%$ of the patients had an AHI of $>10$ events/hr with $16 \%$ having OSA and $11 \%$ CSA (76). It is important to note, however, that half the patients who did not meet the criteria for sleep apnoea were on nocturnal oxygen for their pulmonary hypertension, which may have masked the presence of OSA.

\section{Prevalence of pulmonary hypertension in patients with OSA}

Conversely, the prevalence of pulmonary hypertension in OSA ranges between $17-53 \%$ (77). Factors contributing to this variance include lack of standardization in the definition of pulmonary hypertension, differences in the methods used to diagnose pulmonary hypertension (e.g., echocardiogram $v s$. right heart catheter) and lack of exclusion in some studies of patients with concurrent left heart disease or lung diseases. In a sub sample of the Framingham Heart Study cohort, right ventricular remodeling was evaluated in 90 patients with sleep disordered breathing as defined by a respiratory disturbance index (RDI) of $>90^{\text {th }}$ centile and compared to 90 matched controls with a low RDI (mean RDI 5). Right ventricular wall thickness, as assessed by echocardiogram, was seen to be significantly greater after multivariable adjustment in patients with sleep disordered breathing compared to those without $(0.78 v s .0 .68 \pm 0.02 \mathrm{~cm}$ respectively, $\mathrm{P}=0.005$ ) (78). In a prospective study of 220 patients with OSA with an AHI $>20$ events/hr, a diagnosis of pulmonary hypertension made by right heart catherization demonstrated a prevalence of $17 \%$. Of note, the study defined pulmonary hypertension as a resting pulmonary arterial pressure of $>20 \mathrm{mmHg}$ whereas the latest definition of pulmonary hypertension is an elevation in mean arterial pressure of $>25 \mathrm{mmHg}$ at rest (75). In a retrospective study that used $>25 \mathrm{mmHg}$ to define pulmonary hypertension, the prevalence of pulmonary hypertension in patients with OSA was $22 \%$, however, this study did not exclude patients who had concurrent pulmonary disease (79). Doppler studies have found a similar prevalence. In a study by Sajkov et al., $34 \%$ of patients with OSA who underwent echocardiogram had a mean pulmonary arterial pressure of $>20 \mathrm{mmHg}(80)$. Patients with lung disease were excluded but the threshold for defining pulmonary hypertension was lower than what current guidelines recommend. Even though pulmonary hypertension is prevalent in patients with OSA, the overall severity is mild with a mean pulmonary arterial pressure ranging between 22 to $40 \mathrm{mmHg}$ (77). Nocturnal hypoxia, older age, higher BMI and co-existent lung disease seem to be predictors of developing pulmonary hypertension. However, no significant association between the severity of OSA and subsequent pulmonary hypertension development has been seen (77).

\section{Effects of treatment of OSA on pulmonary hypertension}

There are no epidemiological studies reporting the effect of CPAP treatment on the development or resolution of pulmonary hypertension and right heart strain. There are data from observational studies suggesting that CPAP treatment of OSA in patients with pulmonary hypertension improves right heart function and reduces pulmonary pressures $(81,82)$. In a randomised cross over trial evaluating CPAP versus sham CPAP, CPAP therapy was seen to reduce pulmonary arterial pressures by $6 \mathrm{mmHg}$ with the most 
significant effects observed in patients who had pulmonary hypertension or left ventricular dysfunction at baseline (83). Although right heart failure is a late-stage complication of pulmonary hypertension, its presence in patients with sleepdisordered breathing has been shown to be associated with a significantly shorter event free survival in a cohort of 202 patients (84).

To summarise, the limited epidemiological data suggests that pulmonary hypertension is not uncommon in patients with OSA; however, there is insufficient evidence to recommend screening for this. In contrast, screening for OSA in pulmonary hypertension has been recommended by the American College of Cardiology and the American Heart Association as it is an established aetiology of pulmonary hypertension and treating the OSA may limit the adverse pulmonary vascular effects (85).

\section{Cardiovascular mortality}

The majority of observational studies suggest that untreated OSA increases cardiovascular mortality and morbidity (19). An 18-year follow up of the WSC showed that after excluding people who had received CPAP treatment, the adjusted HR for cardiovascular mortality was 5.2 (95\% CI, 1.4-19.2) (86). An 8-year follow up of SHHS cohort published around the same time also showed a similar outcome albeit a weaker association with narrower confidence intervals (HR 1.46; 95\% CI, 1.14-1.86) (12). Marin et al. demonstrated in a large observational study of men that those with severe untreated sleep apnoea were up to 3 times more likely to have a fatal cardiovascular event compared to those who were simple snorers and those with severe OSA that were treated with CPAP (64). On the other hand, the 20-year follow of 400 patients of the Busselton Health Cohort found that moderate to severe OSA was associated with increased all cause mortality (HR 4.2 ; 95\% CI, 1.9-9.2) but not significantly associated with cardiovascular disease and coronary heart disease, which the authors attributed to the low overall cardiovascular disease rates in Busselton, Western Australia (87). There are a few studies that have investigated cardiovascular endpoints in REM OSA. In a 9-year follow up study of 3,265 patients from the Sleep Heart Health Study who had a baseline nonREM AHI of $<5$ events/hr, the adjusted HR for a composite cardiovascular endpoint (inclusive of cardiovascular death) amongst those with severe REM OSA (REM AHI $>30$ events/hr) was 1.35 (95\% CI, 0.98-1.85) after accounting for demographic characteristics, smoking, hypertension and diabetes. Further stratification showed that this association was driven by those patients who had prevalent cardiovascular disease plus severe REM OSA (88). Studies looking at the therapeutic effects of CPAP on cardiovascular outcomes in REM OSA are yet to be conducted.

\section{Conclusions}

The epidemiological data on OSA and sleep disordered breathing in relation to cardiovascular disease is extensive and is constantly evolving with increased awareness of sleep disordered breathing. This chapter demonstrates that untreated sleep apnoea is associated with prevalent and incident hypertension, stroke, CAD and heart failure. The recent trend for re-analysis of cohort study data to examine REM predominant sleep apnoea, and the various components of OSA physiology (e.g., hypoxic burden versus sleep disruption) is promising to provide new insights into how OSA is linked to increased CV risk. There are some observational data that support treatment of OSA for CV risk reduction, although the RCT evidence to date does not support this. The effects of sleep apnea treatment on CV risk are yet to be fully explored (89). Further areas of collaborative research with cardiovascular investigators should focus on risk stratification of OSA patients in terms of adverse cardiovascular outcomes, including the identification of new OSA-specific biomarkers of CV risk, and the enrollment of such high-risk OSA patients in randomized controlled trials.

\section{Acknowledgements}

None.

\section{Footnote}

Conflicts of Interest: The authors have no conflicts of interest to declare.

\section{References}

1. Young T, Skatrud J, Peppard PE. Risk factors for obstructive sleep apnea in adults. JAMA 2004;291:2013-6.

2. Sweetman AM, Lack LC, Catcheside PG, et al. Developing a successful treatment for co-morbid insomnia and sleep apnoea. Sleep Med Rev 2017;33:28-38.

3. Ye L, Pien GW, Ratcliffe SJ, et al. The different clinical 
faces of obstructive sleep apnoea: a cluster analysis. Eur Respir J 2014;44:1600-7.

4. Peppard PE, Young T, Barnet JH, et al. Increased prevalence of sleep-disordered breathing in adults. Am J Epidemiol 2013;177:1006-14.

5. Punjabi NM. The Epidemiology of Adult Obstructive Sleep Apnea. Proceedings of the American Thoracic Society 2008;5:136-43.

6. Young T, Palta M, Dempsey J, et al. The occurrence of sleep-disordered breathing among middle-aged adults. $\mathrm{N}$ Engl J Med 1993;328:1230-5.

7. Heinzer R, Vat S, Marques-Vidal P, et al. Prevalence of sleep-disordered breathing in the general population: the HypnoLaus study. Lancet Respir Med 2015;3:310-8.

8. Adams R, Appleton S, Taylor A, et al. Are the ICSD-3 criteria for sleep apnoea syndrome too inclusive? Lancet Respir Med 2016;4:e19-20.

9. Jennum P, Riha RL. Epidemiology of sleep apnoea/ hypopnoea syndrome and sleep-disordered breathing. Eur Respir J 2009;33:907-14.

10. Koskenvuo M, Partinen M, Sarna S, et al. Snoring as a risk factor for hypertension and angina pectoris. Lancet 1985;1:893-6.

11. Peppard PE, Young T, Palta M, et al. Prospective study of the association between sleep-disordered breathing and hypertension. N Engl J Med 2000;342:1378-84.

12. Punjabi NM, Caffo BS, Goodwin JL, et al. SleepDisordered Breathing and Mortality: A Prospective Cohort Study. PLoS Med 2009;6:e1000132.

13. Gottlieb DJ, Yenokyan G, Newman AB, et al. Prospective study of obstructive sleep apnea and incident coronary heart disease and heart failure: the sleep heart health study. Circulation 2010;122:352-60.

14. McNicholas WT, Bonsignore MR. Sleep apnoea as an independent risk factor for cardiovascular disease: current evidence, basic mechanisms and research priorities. Eur Respir J 2007;29:156-78.

15. Xu S, Wan Y, Xu M, et al. The association between obstructive sleep apnea and metabolic syndrome: a systematic review and meta-analysis. BMC Pulm Med 2015;15:105.

16. Stone KL, Blackwell TL, Ancoli-Israel S, et al. Sleep Disordered Breathing and Risk of Stroke in Older Community-Dwelling Men. Sleep 2016;39:531-40.

17. Xie J, Sert Kuniyoshi FH, Covassin N, et al. Nocturnal Hypoxemia Due to Obstructive Sleep Apnea Is an Independent Predictor of Poor Prognosis After Myocardial Infarction. J Am Heart Assoc 2016;5.
18. Kass JE, Akers SM, Bartter TC, et al. Rapid-eyemovement-specific sleep-disordered breathing: a possible cause of excessive daytime sleepiness. Am J Respir Crit Care Med 1996;154:167-9.

19. Sanchez-de-la-Torre M, Campos-Rodriguez F, Barbe F. Obstructive sleep apnoea and cardiovascular disease. Lancet Respir Med 2013;1:61-72.

20. Kohler M, Stradling JR. Mechanisms of vascular damage in obstructive sleep apnea. Nat Rev Cardiol 2010;7:677-85.

21. Phillips CL, O'Driscoll DM. Hypertension and obstructive sleep apnea. Nat Sci Sleep 2013;5:43-52.

22. Young T, Peppard P, Palta M, et al. Population-based study of sleep-disordered breathing as a risk factor for hypertension. Arch Intern Med 1997;157:1746-52.

23. Nieto FJ, Young TB, Lind BK, et al. Association of sleepdisordered breathing, sleep apnea, and hypertension in a large community-based study. Sleep Heart Health Study. JAMA 2000;283:1829-36.

24. Haas DC, Foster GL, Nieto FJ, et al. Age-dependent associations between sleep-disordered breathing and hypertension: importance of discriminating between systolic/diastolic hypertension and isolated systolic hypertension in the Sleep Heart Health Study. Circulation 2005;111:614-21.

25. Bixler EO, Vgontzas AN, Lin HM, et al. Association of hypertension and sleep-disordered breathing. Arch Intern Med 2000;160:2289-95.

26. Glasser M, Bailey N, McMillan A, et al. Sleep apnoea in older people. Breathe 2011;7:248.

27. Lavie P, Herer P, Hoffstein V. Obstructive sleep apnoea syndrome as a risk factor for hypertension: population study. BMJ 2000;320:479-82.

28. Tkacova R, McNicholas WT, Javorsky M, et al. Nocturnal intermittent hypoxia predicts prevalent hypertension in the European Sleep Apnoea Database cohort study. Eur Respir J 2014;44:931.

29. Marin JM, Agusti A, Villar I, et al. Association between treated and untreated obstructive sleep apnea and risk of hypertension. JAMA 2012;307:2169-76.

30. O'Connor GT, Caffo B, Newman AB, et al. Prospective study of sleep-disordered breathing and hypertension: the Sleep Heart Health Study. Am J Respir Crit Care Med 2009;179:1159-64.

31. Cano-Pumarega I, Duran-Cantolla J, Aizpuru F, et al. Obstructive sleep apnea and systemic hypertension: longitudinal study in the general population: the Vitoria Sleep Cohort. Am J Respir Crit Care Med 2011;184:1299-304. 
32. Mokhlesi B, Finn LA, Hagen EW, et al. Obstructive Sleep Apnea during REM Sleep and Hypertension. Results of the Wisconsin Sleep Cohort. Am J Respir Crit Care Med 2014;190:1158-67.

33. Boggia J, Li Y, Thijs L, et al. Prognostic accuracy of day versus night ambulatory blood pressure: a cohort study. Lancet 2007;370:1219-29.

34. Staessen JA, Thijs L, Fagard R, et al. Predicting cardiovascular risk using conventional vs ambulatory blood pressure in older patients with systolic hypertension. JAMA 1999;282:539-46.

35. Appleton SL, Vakulin A, Martin SA, et al. Hypertension Is Associated With Undiagnosed OSA During Rapid Eye Movement Sleep. Chest 2016;150:495-505.

36. Van Ryswyk E, Mukherjee S, Chai-Coetzer CL, et al. Sleep Disorders, Including Sleep Apnea, and Hypertension. Am J Hypertens 2018;31:857-64.

37. Iftikhar IH, Valentine CW, Bittencourt LR, et al. Effects of continuous positive airway pressure on blood pressure in patients with resistant hypertension and obstructive sleep apnea: a meta-analysis. J Hypertens 2014;32:234150; discussion 2350.

38. Thomopoulos C, Michalopoulou H, Kasiakogias A, et al. Resistant Hypertension and Obstructive Sleep Apnea: The Sparring Partners. International Journal of Hypertension 2011;2011:947246.

39. Kohli P, Balachandran JS, Malhotra A. Obstructive Sleep Apnea and the Risk for Cardiovascular Disease. Curr Atheroscler Rep 2011;13:138-46.

40. Mehra R, Benjamin EJ, Shahar E, et al. Association of nocturnal arrhythmias with sleep-disordered breathing: The Sleep Heart Health Study. Am J Respir Crit Care Med 2006;173:910-6.

41. Linz D, McEvoy RD, Cowie MR, et al. Associations of Obstructive Sleep Apnea With Atrial Fibrillation and Continuous Positive Airway Pressure Treatment: A Review. JAMA Cardiol 2018;3:532-40.

42. Javaheri S, Parker TJ, Liming JD, et al. Sleep apnea in 81 ambulatory male patients with stable heart failure. Types and their prevalences, consequences, and presentations. Circulation 1998;97:2154-9.

43. Mooe T, Gullsby S, Rabben T, et al. Sleep-disordered breathing: a novel predictor of atrial fibrillation after coronary artery bypass surgery. Coron Artery Dis 1996;7:475-8.

44. Gami AS, Pressman G, Caples SM, et al. Association of atrial fibrillation and obstructive sleep apnea. Circulation 2004;110:364-7.
45. Stevenson IH, Teichtahl H, Cunnington D, et al. Prevalence of sleep disordered breathing in paroxysmal and persistent atrial fibrillation patients with normal left ventricular function. Eur Heart J 2008;29:1662-9.

46. Zhao E, Chen S, Du Y, et al. Association between Sleep Apnea Hypopnea Syndrome and the Risk of Atrial Fibrillation: A Meta-Analysis of Cohort Study. Biomed Res Int 2018;2018:5215868.

47. Gami AS, Hodge DO, Herges RM, et al. Obstructive sleep apnea, obesity, and the risk of incident atrial fibrillation. J Am Coll Cardiol 2007;49:565-71.

48. $\mathrm{Ng} \mathrm{CY,} \mathrm{Liu} \mathrm{T,} \mathrm{Shehata} \mathrm{M,} \mathrm{et} \mathrm{al.} \mathrm{Meta-analysis} \mathrm{of}$ obstructive sleep apnea as predictor of atrial fibrillation recurrence after catheter ablation. Am J Cardiol 2011;108:47-51.

49. Digby GC, Baranchuk A. Sleep Apnea and Atrial Fibrillation; 2012 Update. Curr Cardiol Rev 2012;8:265-72.

50. Rossi VA, Stradling JR, Kohler M. Effects of obstructive sleep apnoea on heart rhythm. Eur Respir J 2013;41:1439-51.

51. Fleg JL, Kennedy HL. Cardiac Arrhythmias in a Healthy Elderly Population. Chest 1982;81:302-7.

52. Becker HF, Koehler U, Stammnitz A, et al. Heart block in patients with sleep apnoea. Thorax 1998;53 Suppl 3:S29-32.

53. Koshino Y, Satoh M, Katayose Y, et al. Association of Sleep-Disordered Breathing and Ventricular Arrhythmias in Patients Without Heart Failure. Am J Cardiol 2008;101:882-6.

54. Olmetti F, La Rovere MT, Robbi E, et al. Nocturnal cardiac arrhythmia in patients with obstructive sleep apnea. Sleep Med 2008;9:475-80.

55. Birkbak J, Clark AJ, Rod NH. The Effect of Sleep Disordered Breathing on the Outcome of Stroke and Transient Ischemic Attack: A Systematic Review. J Clin Sleep Med 2014;10:103-8.

56. Lattimore JD, Celermajer DS, Wilcox I. Obstructive sleep apnea and cardiovascular disease. J Am Coll Cardiol 2003;41:1429-37.

57. Dong R, Dong Z, Liu H, et al. Prevalence, Risk Factors, Outcomes, and Treatment of Obstructive Sleep Apnea in Patients with Cerebrovascular Disease: A Systematic Review. J Stroke Cerebrovasc Dis 2018;27:1471-80.

58. Loke YK, Brown JWL, Kwok CS, et al. Association of Obstructive Sleep Apnea With Risk of Serious Cardiovascular Events. Circ Cardiovasc Qual Outcomes 2012;5:720. 
59. Yaranov DM, Smyrlis A, Usatii N, et al. Effect of Obstructive Sleep Apnea on Frequency of Stroke in Patients With Atrial Fibrillation. Am J Cardiol 2015;115:461-5.

60. Rola R, Jarosz H, Wierzbicka A, et al. Sleep disorderd breathing and recurrence of cerebrovascular events, casefatality, and functional outcome in patients with ischemic stroke or transient ischemic attack. J Physiol Pharmacol 2008;59 Suppl 6:615-21.

61. Sahlin C, Sandberg O, Gustafson Y, et al. Obstructive sleep apnea is a risk factor for death in patients with stroke: a 10-year follow-up. Arch Intern Med 2008;168:297-301.

62. Javaheri S, Barbe F, Campos-Rodriguez F, et al. Sleep Apnea: Types, Mechanisms, and Clinical Cardiovascular Consequences. J Am Coll Cardiol 2017;69:841-58.

63. Hla KM, Young T, Hagen EW, et al. Coronary heart disease incidence in sleep disordered breathing: the Wisconsin Sleep Cohort Study. Sleep 2015;38:677-84.

64. Marin JM, Carrizo SJ, Vicente E, et al. Long-term cardiovascular outcomes in men with obstructive sleep apnoea-hypopnoea with or without treatment with continuous positive airway pressure: an observational study. Lancet 2005;365:1046-53.

65. Buchner NJ, Sanner BM, Borgel J, et al. Continuous positive airway pressure treatment of mild to moderate obstructive sleep apnea reduces cardiovascular risk. Am J Respir Crit Care Med 2007;176:1274-80.

66. Peker Y, Glantz H, Eulenburg C, et al. Effect of Positive Airway Pressure on Cardiovascular Outcomes in Coronary Artery Disease Patients with Nonsleepy Obstructive Sleep Apnea. The RICCADSA Randomized Controlled Trial. Am J Respir Crit Care Med 2016;194:613-20.

67. McEvoy RD, Antic NA, Heeley E, et al. CPAP for Prevention of Cardiovascular Events in Obstructive Sleep Apnea. N Engl J Med 2016;375:919-31.

68. Rosen D, Roux FJ, Shah N. Sleep and breathing in congestive heart failure. Clin Chest Med 2014;35:521-34.

69. Sekizuka H, Osada N, Miyake F. Sleep disordered breathing in heart failure patients with reduced versus preserved ejection fraction. Heart Lung Circ 2013;22:104-9.

70. Jelic S, Le Jemtel TH. Sleep-disordered breathing in acute decompensated heart failure. Curr Heart Fail Rep 2009;6:169-75.

71. Lévy P, Pépin J-L, Tamisier R, et al. Prevalence and Impact of Central Sleep Apnea in Heart Failure. Sleep Med Clin 2007;2:615-21.

72. Bitter T, Faber L, Hering D, et al. Sleep-disordered breathing in heart failure with normal left ventricular ejection fraction. Eur J Heart Fail 2009;11:602-8.

73. Roca GQ, Redline S, Claggett B, et al. Sex-Specific Association of Sleep Apnea Severity with Subclinical Myocardial Injury, Ventricular Hypertrophy, and Heart Failure Risk in a Community Dwelling Cohort: The Atherosclerosis Risk in Communities-Sleep Heart Health Study. Circulation 2015;132:1329-37.

74. Arzt M, Young T, Finn L, et al. Sleepiness and sleep in patients with both systolic heart failure and obstructive sleep apnea. Arch Intern Med 2006;166:1716-22 .

75. Simonneau G, Gatzoulis MA, Adatia I, et al. Updated clinical classification of pulmonary hypertension. J Am Coll Cardiol 2013;62:D34-41.

76. Dumitrascu R, Tiede H, Eckermann J, et al. Sleep apnea in precapillary pulmonary hypertension. Sleep Med 2013;14:247-51.

77. Wong HS, Williams A, Mok Y. The relationship between pulmonary hypertension and obstructive sleep apnea. Curr Opin Pulm Med 2017;23:517-21.

78. Guidry UC, Mendes LA, Evans JC, et al. Echocardiographic features of the right heart in sleepdisordered breathing: the Framingham Heart Study. Am J Respir Crit Care Med 2001;164:933-8.

79. Minai OA, Ricaurte B, Kaw R, et al. Frequency and impact of pulmonary hypertension in patients with obstructive sleep apnea syndrome. Am J Cardiol 2009;104:1300-6.

80. Sajkov D, Wang T, Saunders NA, et al. Daytime pulmonary hemodynamics in patients with obstructive sleep apnea without lung disease. Am J Respir Crit Care Med 1999;159:1518-26.

81. Javaheri S, Javaheri S, Javaheri A. Sleep apnea, heart failure, and pulmonary hypertension. Curr Heart Fail Rep 2013;10:315-20.

82. Kholdani C, Fares WH, Mohsenin V. Pulmonary hypertension in obstructive sleep apnea: is it clinically significant? A critical analysis of the association and pathophysiology. Pulmonary Circulation 2015;5:220-7.

83. Arias MA, Garcia-Rio F, Alonso-Fernandez A, et al. Pulmonary hypertension in obstructive sleep apnoea: effects of continuous positive airway pressure: a randomized, controlled cross-over study. Eur Heart J 2006;27:1106-13.

84. Kusunose K, Phelan D, Seicean S, et al. Relation of Echocardiographic Characteristics of the Right-Sided Heart With Incident Heart Failure and Mortality in Patients With Sleep-Disordered Breathing and Preserved Left Ventricular Ejection Fraction. Am J Cardiol 
2016;118:1268-73.

85. McLaughlin VV, Archer SL, Badesch DB, et al. ACCF/ AHA 2009 expert consensus document on pulmonary hypertension a report of the American College of Cardiology Foundation Task Force on Expert Consensus Documents and the American Heart Association developed in collaboration with the American College of Chest Physicians; American Thoracic Society, Inc.; and the Pulmonary Hypertension Association. J Am Coll Cardiol 2009;53:1573-619.

86. Young T, Finn L, Peppard PE, et al. Sleep disordered breathing and mortality: eighteen-year follow-up of the

Cite this article as: Sarkar P, Mukherjee S, Chai-Coetzer CL, McEvoy RD. The epidemiology of obstructive sleep apnoea and cardiovascular disease. J Thorac Dis 2018;10(Suppl 34):S4189S4200. doi: 10.21037/jtd.2018.12.56
Wisconsin sleep cohort. Sleep 2008;31:1071-8.

87. Marshall NS, Wong KK, Cullen SR, et al. Sleep apnea and 20-year follow-up for all-cause mortality, stroke, and cancer incidence and mortality in the Busselton Health Study cohort. J Clin Sleep Med 2014;10:355-62.

88. Aurora RN, Crainiceanu C, Gottlieb DJ, et al. Obstructive Sleep Apnea during REM Sleep and Cardiovascular Disease. Am J Respir Crit Care Med 2018;197:653-60.

89. Drager LF, McEvoy RD, Barbe F, et al. Sleep Apnea and Cardiovascular Disease: Lessons From Recent Trials and Need for Team Science. Circulation 2017;136:1840-50. 